\title{
Decidual cytokines and pregnancy complications: focus on spontaneous miscarriage
}

\author{
Gendie E. Lash and Jan Ernerudh
}

\section{Linköping University Post Print}

\section{Tweet}

N.B.: When citing this work, cite the original article.

Original Publication:

Gendie E. Lash and Jan Ernerudh, Decidual cytokines and pregnancy complications: focus on spontaneous miscarriage, 2015, Journal of Reproductive Immunology, (108), 83-89.

http://dx.doi.org/10.1016/j.jri.2015.02.003

Copyright: Elsevier

http://www.elsevier.com/

Postprint available at: Linköping University Electronic Press

http://urn.kb.se/resolve?urn=urn:nbn:se:liu:diva-118252 
Decidual cytokines and pregnancy complications: focus on spontaneous miscarriage

Gendie E Lash ${ }^{1 *}$ and Jan Ernerudh ${ }^{2}$

${ }^{1}$ Reproductive and Vascular Biology Group, Institute of Cellular Medicine, Newcastle University, Newcastle upon Tyne, UK; ${ }^{2}$ Clinical Immunology, Department of Clinical and Experimental Medicine, Faculty of Health Sciences, Linköping University, Linköping, Sweden.

*Address for correspondence:

Dr Gendie Lash

Reproductive and Vascular Biology Group

Institute of Cellular Medicine

$3^{\text {rd }}$ Floor, William Leech Building

Newcastle University

Newcastle upon Tyne

NE2 4HH, UK

Email: gendie.lash@ncl.ac.uk

Phone: +44 1912088578 


\section{Abstract}

The establishment of pregnancy requires the co-ordinated implantation of the embryo into the receptive decidua, placentation, trophoblast invasion of the maternal decidua and myometrium as well as remodelling of the uterine spiral arteries. Failure of any of these steps can lead to a range of pregnancy complications including miscarriage, pre-eclampsia, fetal growth restriction, placenta accreta and pre-term birth. Cytokines are small multifunctional proteins often derived from leucocytes and have primarily been described through their immunomodulatory actions. The maternal-fetal interface is considered to be immunosuppressed to allow development of the semi-allogeneic placental-fetal unit. However, cytokine profiles of the decidua and different decidual cell types suggests that the in vivo situation is more complex. Data suggests that decidual derived cytokines not only play roles in immunosuppression but also in other aspects of the establishment of pregnancy including regulation of trophoblast invasion and spiral artery remodelling. This review focuses on the potential role of decidual derived cytokines in the aetiology of unexplained spontaneous miscarriage.

Keywords: decidua; cytokines; miscarriage; trophoblast invasion; spiral artery remodelling 


\section{$1 \quad$ Introduction}

Several pregnancy pathologies, including pre-eclampsia (PE), fetal growth restriction (FGR) and miscarriage, are associated with deficient invasion of extravillous trophoblast cells (EVT) into the decidua and myometrium as well as incomplete remodelling of the uterine spiral arteries. EVT invasion and remodelling of the uterine spiral arteries are highly complex processes that require the dynamic interplay of many different biological signals from different cellular sources, including the decidua. Of particular note are the decidual cytokines and how their dysregulation may play roles in the aetiology of complications of pregnancy. This review will discuss the pathophysiology of spontaneous miscarriage, key processes in the establishment of pregnancy that may be causative of this pregnancy complication as well as decidual cytokines shown to be dysregulated in miscarriage, their cellular sources, known functions and how they may contribute to the pathogenesis of miscarriage.

\section{$2 \quad$ Cytokines}

Cytokines are small (5-20kDa) signalling proteins produced by a wide range of cells. They show diverse functions, including regulation of cellular invasion and both humoral and cellbased immune responses. These cell-based and humoral immune responses are mediated by different sets of cytokines that can be grouped according to their main function for example; pro- and anti-inflammatory, or associated with different $\mathrm{T}$ helper (Th) subsets referred to as Th1, Th2, Th17 and regulatory (Treg) cells. Major pro-inflammatory cytokines include TNF, IL-1 $\beta$, IL-6 and CXCL8/IL-8, while anti-inflammatory cytokines include IL-10 and 
TGF- $\beta$. Signature cytokines of Th-associated responses are; interferon (IFN)- - (Th1); IL-4, IL5, IL-9 and IL-13 (Th2); IL-17A and IL-17E (Th17); IL-10 and TGF- $\beta$ (Treg). Several other cytokines also exist that do not precisely fit into the described groups, like interferons, chemokines, growth factors and many others. The area is complex because of a redundancy in cytokines with antagonistic, synergistic, similar and sometimes identical effects; for instance, there are at least 37 interleukins and approximately 50 chemokines. In this review we will focus on a limited number of established and well-known cytokines in reproductive biology, but also include recent advances that confirm or challenge our understanding of this complex area of biology.

\section{Cytokines in normal pregnancy}

In the early era after the discovery of the Th1/Th2 dichotomy, Wegmann et al. (1993) proposed that during pregnancy a Th2 response prevails, whereas a Th1 response is detrimental to pregnancy. From a general perspective and when considering systemic changes, this view is supported by observations like the improvement of Th1-associated autoimmune disease multiple sclerosis (Confavreux et al., 1998) and rheumatoid arthrirtis (Ostensen and Villiger, 2007) during pregnancy. However, this view is likely too simplistic as Th1 cytokines have also been shown to be essential for maintenance of pregnancy, e.g. IFN$\gamma$ is essential for successful pregnancy as it is pivotal in spiral artery remodelling and successful pregnancy outcome (Ashkar et al., 2000; Croy et al., 2003; Robson et al., 2012). Furthermore, a study using a Th2 knockout (IL-4, IL-5, IL-9 and IL-13 ko) mouse showed normal reproductive outcome (Fallon et al., 2002), although different systems may be involved in maintenance of mouse and human pregnancies. Additional cytokines, e.g. IL-15 
and IL-18, which are not classed as Th1 or Th2 type cytokines, have been observed at the maternal-fetal interface (Chaouat et al., 2002; Murphy et al., 2009), and the broadening of the Th subset families to include Th17 and Treg has indeed challenged the paradigm and adding to its complexity. Although IL-17 has been mostly associated with hyperinflammation in autoimmunity, it was recently suggested that stromal cell-derived IL-17 was present in the first trimester and had a positive role in sustaining human pregnancy by recruiting Th17 cells, and promoting trophoblast invasion and inhibiting trophoblast apoptosis (Wu et al., 2014). Conversely, Th17 cells have been reported to be rare and outnumbered by an enrichment of Treg cells (Mjösberg et al., 2010).

The human endometrium produces a wide variety of cytokines throughout the proliferative and secretory phase of the menstrual cycle (Tabibzadeh, 1991). These cytokines are believed to play a significant role in the modulation of the uterine environment preparing the uterus for implantation of the developing conceptus and formation of a functional placenta during the establishment of pregnancy.

Prevention of maternal rejection of the fetus requires a regulated environment, which occurs primarily at the maternal-fetal interface and the uterine tissues. Classically, naive $\mathrm{CD}^{+}{ }^{+}$T-cells are the major producers of cytokines divided into the subsets of Th1, Th2, Th17 and Treg. However, at the maternal-fetal interface a plethora of Th-associated cytokines are also produced by trophoblast cells, stromal cells, epithelial cells, maternal T lymphocytes, macrophages, natural killer (NK) cells and other maternal leucocytes (Vince and Johnson, 2000), suggesting that maintenance and development of the fetal-placental unit is dependent on these cytokines. The presence of cytokines at the maternal-fetal interface may influence the environment by regulating processes such as implantation, 
placental development, cytotrophoblast proliferation, angiogenesis, extravillous trophoblast cell (EVT) invasion, spiral artery remodelling, cellular growth and apoptosis, as well as induction of fetal tolerance (Piccinni et al., 2000; Drake et al., 2001; Dimitriadis et al., 2005; Lash et al., 2006; Murphy et al., 2009). However, this is a complex area of research due to the pleiotropy and redundancy of the cytokine network.

\section{$3 \quad$ Miscarriage}

Miscarriage is the commonest gynaecological emergency (70000-90000 per year in England and Wales) (Everett, 1997) and has huge financial and personal implications. The vast majority of miscarriages occur in healthy women during the first trimester of pregnancy. Between 11 and $20 \%$ of all clinically recognised pregnancies are lost before the 20th week of gestation. Most miscarriages are sporadic, that is they are non-recurring although a sub-set of women do suffer from recurrent miscarriage defined as three or more consecutive miscarriages. It is likely that the aetiology of sporadic and recurrent miscarriage differs and therefore this article will focus on sporadic or spontaneous miscarriage.

Approximately $50 \%$ of miscarriages are associated with chromosomal abnormalities (aneuploidy) (Jauniaux and Hustin, 1992). However, the cause in the remaining $50 \%$ is unknown and the mechanisms involved in sporadic first trimester miscarriages are poorly understood (Hustin et al., 1996), and it is these idiopathic cases that we will concentrate on in this review.

Approximately $70 \%$ of early miscarriages have been associated with premature and continuous intervillous blood flow, evidence arising from flow patterns using gray scale 
Doppler. This was linked to oxidative stress in villous trophoblast, an effect of a thin and disrupted trophoblast shell (Jauniaux et al., 1994; Jauniaux et al., 2000). There is also evidence suggesting that deficient trophoblast invasion may be linked with first trimester miscarriage; using a morphological method (Hustin et al., 1990) demonstrated reduced trophoblast invasion in early aneuploid miscarriages. It was this observation that led to the suggestion that trophoblast invasion and spiral artery remodelling are primarily reduced in miscarriage, although reports are inconsistent. Ball et al. (2006a) assessed trophoblast subpopulations and spiral artery transformation in placental bed biopsies from sporadic miscarriage cases ( $n=73)$ compared with controls $(n=179)$, using an immunohistochemical approach. In contrast to Hustin et al. (1990) there was no evidence of failure of trophoblast invasion and abnormal spiral artery remodelling in the decidua or myometrium in early $(\leq 12+6$ weeks gestational age) miscarriage, suggesting that these processes do not have a pivotal role in the pathogenesis of early miscarriage. The varying results between the different studies may be due to the tissue sampled; the abnormalities in early miscarriages were detected in studies generally using aspirated gestational sacs which include cytotrophoblast cell columns and the cytotrophoblast shell (Hustin et al., 1990); whereas, placental bed biopsies extend deeper into the uterine wall (Ball et al., 2006a). However, reduced trophoblast invasion and spiral artery remodelling in late ( $\geq 13$ weeks gestational age) miscarriage was observed (Ball et al., 2006b).

\section{$4 \quad$ Decidua}

Symbiotic signalling between the blastocyst and mother is necessary for successful pregnancy and requires a highly receptive endometrium (decidua) during the window of 
implantation (Aplin, 2000). The decidua is comprised of luminal and glandular epithelium, stromal cells, spiral arteries, lymphatics and leucocytes. In the first trimester of pregnancy, approximately $30-40 \%$ of the cells in the decidual stroma are leucocytes, primarily uterine natural killer (uNK) cells, macrophages and T lymphocytes (Bulmer et al., 1991) although other less abundant but functionally important endometrial leucocyte populations are also present including dendritic cells (Gardner and Moffett, 2003), natural killer T (NKT) (Tsuda et al., 2001) cells and regulatory T cells (Mjösberg et al., 2010; Ernerudh et al., 2011). The decidua is a rich source of cytokines, growth factors and proteases that may contribute to regulation of EVT invasion and spiral artery remodelling.

\section{$5 \quad$ Trophoblast invasion}

EVT are naturally highly invasive although their invasion into the decidua and inner third of the myometrium is tightly regulated. In simple terms there are three general features of cellular invasion; attachment to the extracellular matrix (ECM), proteolytic breakdown of the ECM and then movement into that cleared space prior to reattachment. EVT invasiveness is associated with their phenotype, for example EVT express a unique repertoire of cell surface integrins, distinct from those expressed by villous cytotrophoblast (CTB). In particular, EVT are characterised by the expression of $\alpha 1 \beta 1$ and $\alpha 5 \beta 1$ integrins, while CTB express $\alpha 6 \beta 4$ integrin (Damsky et al., 1992). This switch in integrin expression appears to be essential for the invasive phenotype of EVT (Damsky et al., 1994). Many different factors (growth factors, cytokines and chemokines) have been shown to regulate trophoblast invasion in in vitro models, and it is likely that in vivo relative local concentrations of these different compounds play roles in stimulation or inhibition of the 
invasive process. Whether the natural invasive capacity of EVT is altered in miscarriage has not been investigated and studies have concentrated on alterations in decidual factors that regulate this process.

\section{$6 \quad$ Spiral artery remodelling}

Remodelling of the uterine spiral arteries is one of the most important maternal adaptations to pregnancy (Pijnenborg et al., 2006). During spiral artery remodelling the blood vessels supplying the uterus undergo significant alterations that result in the decidual and superficial myometrial portions of the vessels losing their musculoelastic wall, which is replaced by fibrinoid and intramural EVT (Pijnenborg et al., 2006). This remodelling process allows for maternal blood that is not under vasoactive control to be delivered to the fetalplacental unit. The underlying pathology of pre-eclampsia and fetal growth restriction is associated with reduced spiral artery remodelling, likely from reduced EVT invasion (Khong et al., 1987; Pijnenborg et al., 1991). Spiral artery remodelling is often described in terms of its sequential morphological features which include vascular smooth muscle cell (VSMC) separation, endothelial cell swelling, vessel dilatation, endovascular and/or interstitial EVT invasion, transient loss of endothelial cells, VSMC loss, fibrinoid deposition, presence of intramural EVT and regeneration of the endothelium (Pijnenborg et al., 2006). While EVT are absolutely required for completion of successful spiral artery remodelling the initial steps occur in the absence of EVT, and may be mediated by uNK cells. However, the molecular triggers of spiral artery remodelling are not known and exactly how EVT contribute to this process is also not known. 


\section{$7 \quad$ Homeostasis and tolerance}

The remodelling process involves the production of waste material that needs to be smoothly taken care of. Decidual macrophages and their scavenger receptors are key players in this homoeostatic process (Svensson-Arvelund and Ernerudh, 2014). Along this line, decidual macrophages also take care of threatening microbes without creating hyperinflammation. Decidual macrophages are induced by M-CSF and IL-10 (Svensson et al., 2011); while deficiency of IL-10 has been associated with missed abortion (Plevyak et al., 2002), the role of M-CSF has not been explored in the context of spontaneous miscarriage. Decidual macrophages themselves also contribute by secretion of IL-10 (Lidström et al., 2003, Heikkinen et al., 2003) as well as CCL18 (Gustafsson et al., 2008), and as being the most abundant antigen presenting cells (APC) at the fetal maternal interface they also interact with $\mathrm{T}$ cells thereby contributing to fetal tolerance. In this process, Regulatory $\mathrm{T}$ cells are regarded as the main contributors, with several direct and indirect effects (Ernerudh et al., 2011); IL-6/TGF- $\beta$ and TGF- $\beta /$ IL-10 being the key cytokines in the induction and effector process, respectively.

\section{$8 \quad$ Altered decidual cytokine expression and spontaneous miscarriage}

Altered decidual cytokine expression, involved in the central processes that have been described above, has been shown to be associated with spontaneous miscarriage. However, due to the timing of sample collection it is never fully possible to conclude that this altered expression is causative of the miscarriage or a consequence of fetal and placental demise. 
Some of the major cytokine candidates associated with spontaneous miscarriage are described below (Table 1).

IL-6

IL-6 is a pleiotropic cytokine that is an important mediator in acute-phase responses to injury and infection. It signals through the IL-6 receptor and the gp130 receptor subunit and the Stat pathway to activate target genes involved in cellular differentiation, proliferation, apoptosis and cell survival.

IL-6 is present in human endometrium throughout the menstrual cycle as well as in early pregnancy decidua (Tabibzadeh et al., 1995). It has also been reported that EVT cells express IL-6, and it has been suggested this cytokine can influence trophoblast invasion by up-regulating MMPs (Jauniaux et al., 1996; Meisser et al., 1999; Salamonsen et al., 2007). The role of IL-6 in regulation of EVT invasion remains unclear as different studies report different effects. Jovanovic and Vicovac (2009) reported that both endogenous IL-6 and exogenous IL-6 increased the migration and invasive potential of the trophoblast-like cell line HTR-8/SVneo due to the up-regulation of the trophoblast integrin receptors $\alpha 1, \alpha 5$ and $\beta 5$, receptors which bind to components within the extracellular matrix. However, Champion et al. (2012) reported no effect on EVT invasion from first trimester placental explants. In addition, IL-6 has been shown to induce vascular smooth muscle disorganisation in an in vitro model of spiral artery remodelling (Pitman et al., 2013).

Studies in mouse have demonstrated that increased levels of IL-6 at the maternal-fetal interface were associated with fetal loss (Zenclussen et al., 2003) and more recent data has 
demonstrated increased levels of serum IL-6 in women with second trimester miscarriage compared with levels from first trimester miscarriage (Galazios et al., 2011). However reduced uNK cell and decidual macrophage secreted IL-6 was reported in women with first trimester miscarriage compared with controls, while altered decidual cell expression of IL-6 and its receptors (as determined by immunohistochemistry) was predominantly shown in the placental bed of women with second trimester miscarriage (Pitman et al., 2013).

\section{CXCL8/IL-8}

CXCL8, formerly known as IL-8, is classified as a pro-inflammatory multifunctional CXC chemokine, that signals through the CXCR1 and CXCR2 receptors. CXCL8 is known for its ability to recruit CXCR1 and CXCR2 expressing granulocytes, although these receptors are also expressed on monocytes, NK cells and subpopulations of CD8 cells (Takata et al., 2004). In the early pregnant human decidua, uNK cells are a major producer of CXCL8 (Saito et al., 1994; De Oliveira et al., 2010). There are also reports describing expression of CXCL8 in the pregnant decidua and it is likely to be involved in leucocyte trafficking to the spiral arteries during the first trimester of pregnancy (Hornung et al., 1997; Jones et al., 2004). CXCL8 has been shown to be produced by cells of the placenta, including trophoblast, placental macrophages (Hofbauer cells) and fibroblasts, and it has been suggested that CXCL8 mediates the recruitment and accumulation of neutrophils at the maternal-fetal interface as a defence mechanism against invading bacteria (Shimoya et al., 1999).

CXCL8 has been shown to stimulate trophoblast invasion in in vitro models and contribute to the uNK cell stimulation of trophoblast invasion (Hanna et al., 2006; De Oliveira et al., 2010). 
In addition, CXCL8 induces vascular smooth muscle cell disorganisation in a model of spiral artery remodelling (Pitman et al., 2013).

There are few reports of CXCL8 levels in miscarriage. Madhappan et al. (2003) reported significantly higher levels in products of conception from women with two or more miscarriages $(n=7)$ compared with women with normal pregnancy $(n=4)$ or first miscarriage $(n=12)$. Increased CXCL8 levels in uterine cervical samples have also been associated with women suffering first trimester miscarriage compared with controls (Radulovic et al., 2010). In contrast, reduced levels of CXCL8 were secreted by UNK cells or decidual macrophages isolated from first trimester miscarriage compared with normal controls and expression of CXCL8 and its receptors was altered in the placental bed of women with both early and late miscarriage compared with controls (Pitman et al., 2013).

$T N F-\alpha$

Tumour necrosis factor (TNF) is a potent pro-inflammatory cytokine which elicits its effects via two membrane bound receptors, TNF- $\alpha$ RI and TNF- $\alpha$ RII (Haider and Knofler, 2009). TNF$\alpha$ has been localized to proliferating trophoblast cells in villous tips, interstitial and endovascular EVT in the placental bed (Chen et al., 1991; Pijnenborg et al., 1998), and to a number of decidual cell types including T cells, uNK cells (Jokhi et al., 1994), stromal cells, macrophages (Vince et al., 1992) and endothelial cells (Tabibzadeh, 1991).

TNF has been reported to inhibit trophoblast invasion (Bauer et al., 2004; Renaud et al., 2005; Huber et al., 2006; Otun et al., 2011). The mechanism(s) by which TNF exerts this inhibitory effect likely include alteration of proteolytic enzymes such as the matrix 
metalloproteinases (MMP's) (Bischof et al., 1995) and the urokinase plasminogen activator system (Queenan et al., 1987) as well as altering EVT apoptosis or proliferation (von Rango et al., 2003).

Few studies have investigated TNF in human miscarriage although it has been reported to induce spontaneous abortion in rodents (Chaouat et al., 1990). More recently increased decidual stromal cell secreted levels of TNF have been reported in women with spontaneous miscarriage (Sun et al., 2013).

Other cytokines

Several other cytokines, such as IL-2, IL-1 $\beta$, IL-17A, have also been shown to be dysregulated in the decidua of women miscarriage (Sun et al., 2013; Garzia et al., 2013). However, their roles in establishment of pregnancy have not been well defined, although they do play roles in immune responses. Therefore, it is difficult to speculate whether they have a causative role in the aetiology of miscarriage or are a consequence of this devastating condition.

\section{Conclusions}

Reduced decidual IL-6 and CXCL8/IL-8 as well as increased TNF- $\alpha$ levels may negatively impact on the normal processes of pregnancy establishment by dysregulating control of trophoblast invasion as well as aspects of spiral artery remodelling and therefore contribute to the aetiology of both early and late miscarriage. However, these are very complex 
processes and likely regulated by several different factors, leading to a multifactorial disease state.

Miscarriage remains one of the most prevalent obstetrical complications with little known about risk factors and aetiology. We review here the role that decidual cytokines may play in this process, but owing to the lack of known risk factors or biomarkers for this condition, there is a need for deeper insights into mechanisms before we will be able to translate this knowledge into preventative therapies. 


\section{References}

Aplin, J.D., 2000. The cell biological basis of human implantation. Baillieres Best Pract. Res. Clin. Obstet. Gynaecol. 14, 757-764.

Ashkar, A.A., Di Santo, J.P., Croy, B.A., 2000. Interferon gamma contributes to initiation of uterine vascular modification, decidual integrity, and uterine natural killer cell maturation during normal murine pregnancy. J. Exp. Med. 192, 259-70.

Ball, E., Robson, S.C., Ayis, S., Lyall, F., Bulmer, J.N., 2006a. Early embryonic demise: no evidence of abnormal spiral artery transformation or trophoblast invasion. J. Pathol. 208, 528-534.

Ball, E., Bulmer, J., Ayis, S., Lyall, F., Robson, S., 2006b. Late sporadic miscarriage is associated with abnormalities in spiral artery transformation and trophoblast invasion. J. Pathol. 208, 535-542.

Bauer, S., Pollheimer, J., Hartmann, J., Husslein, P., Aplin, J.D., Knofler, M., 2004. Tumor necrosis factor-alpha inhibits trophoblast migration through elevation of plasminogen activator inhibitor-1 in first-trimester villous explant cultures. J. Clin. Endocrinol. Metab. 89, 812-822.

Bischof, P., Martelli, M., Campana, A., Itoh, Y., Ogata, Y., Nagase, H., 1995. Importance of matrix metalloproteinases in human trophoblast invasion. Early Pregnancy. 1, 263-269.

Bulmer, J.N., Morrison, L., Longfellow, M., Ritson, A., Pace, D., 1991. Granulated lymphocytes in human endometrium: histochemical and immunohistochemical studies. Hum. Reprod. 6, 791-798. 
Champion, H., Innes, B.A., Robson, S.C., Lash, G.E., Bulmer, J.N., 2012. Effects of interleukin6 on extravillous trophoblast invasion in early human pregnancy. Mol. Hum. Reprod. 18, 391-400.

Chaouat, G., Menu, E., Kinsky, R., Brezin, C., 1990. Immunologically mediated abortions: one or several pathways? Res. Immunol. 141, 188-195.

Chaouat, G., Zourbas, S., Ostojic, S., Lappree-Delage, G., Dubanchet, S., Ledee, N., Martal, J., 2002. A brief review of recent data on some cytokine expressions at the materno-foetal interface which might challenge the classical Th1/Th2 dichotomy. J. Reprod. Immunol. 53, 241-256.

Chen, H.L., Yang, Y.P., Hu, X.L., Yelavarthi, K.K., Fishback, J.L., Hunt, J.S., 1991. Tumor necrosis factor alpha mRNA and protein are present in human placental and uterine cells at early and late stages of gestation. Am. J. Pathol. 139, 327-335.

Confavreux, C., Hutchinson, M., Hours, M.M., Cortinovis-Tourniaire, P., Moreau, T., 1998. Rate of pregnancy-related relapse in multiple sclerosis. Pregnancy in Multiple Sclerosis Group. N. Engl. J. Med. 339, 285-291.

Croy, B.A., Esadeg, S., Chantakru, S., Van Den Heuvel, M., Paffaro, V.A., He, H., Black, G.P., Ashkar, A.A., Kiso, Y., Zhang, J., 2003. Update on pathways regulating the activation of uterine Natural Killer cells, their interactions with decidual spiral arteries and homing of their precursors to the uterus. J. Reprod. Immunol. 59, 175-191. 
Damsky, C.H., Fitzgerald, M.L., Fisher, S.J., 1992. Distribution patterns of extracellular matrix components and adhesion receptors are intricately modulated during first trimester differentiation along the invasive pathway, in vivo. J. Clin. Invest. 89, 210-222.

Damsky, C.H., Librach, C., Lim, K.H., Fitzgerald, M.L., McMaster, M.T., Janatpour, M., Zhou, Y., Logan, S.K., Fisher, S.J., 1994. Integrin switching regulates normal trophoblast invasion. Development. 120, 3657-3666.

De Oliveira, L.G., Lash, G.E., Murray-Dunning, C., Bulmer, J.N., Innes, B.A., Searle, R.F., Sass, N., Robson, S.C., 2010. Role of interleukin 8 in uterine natural killer cell regulation of extravillous trophoblast cell invasion. Placenta. 31, 595-601.

Dimitriadis, E., White, C.A., Jones, R.L., Salamonsen, L.A., 2005. Cytokines, chemokines and growth factors in endometrium related to implantation. Hum. Reprod. Update. 11, 613-630.

Drake, P.M., Gunn, M.D., Charo, I.F., Tsou, C.L., Zhou, Y., Huang, L., Fisher, S.J., 2001. Human placental cytotrophoblasts attract monocytes and CD56(bright) natural killer cells via the actions of monocyte inflammatory protein 1alpha. J. Exp. Med. 193, 1199-1212.

Ernerudh, J., Berg, G., Mjösberg, J., 2011. Regulatory T helper cells in pregnancy and their roles in systemic versus local immune tolerance. Am. J. Reprod. Immunol. 66, 31-43.

Fallon, P.G., Jolin, H.E., Smith, P., Emson, C.L., Townsend, M.J., Fallon, R., Smith, P., McKenzie, A.N., 2002. IL-4 induces characteristic Th2 responses even in the combined absence of IL-5, IL-9, and IL-13. Immunity. 17, 7-17. 
Galazios, G., Tsoulou, S., Zografou, C., Tripsianis, G., Koutlaki, N., Papazoglou, D., Tsikouras, P., Maltezos, E., Liberis, V., 2011. The role of cytokines IL-6 and IL-8 in the pathogenesis of spontaneous abortions. J. Matern. Fetal Neonatal. Med. 24, 1283-1285.

Gardner, L., Moffett, A., 2003. Dendritic cells in the human decidua. Biol. Reprod. 69, 14381446.

Garzia, E., Clauser, R., Persani, L., Borgato, S., Bulfamante, G., Avagliano, L., Quadrelli, F., Marconi, A.M., 2013. Prolactin and proinflammatory cytokine expression at the fetomaternal interface in first trimester miscarriage. Fertil. Steril. 100, 108-115.

Gustafsson, C., Mjösberg, J., Matussek, A., Geffers, R., Matthiesen, L., Berg, G., Sharma, S., Buer, J., Ernerudh, J., 2008. Gene expression profiling of human decidual macrophages: evidence for immunosuppressive phenotype. PLoS One. 3, e2078.

Haider, S., Knöfler, M. 2009. Human tumour necrosis factor: physiological and pathological roles in placenta and endometrium. Placenta. 30, 111-123.

Hanna, J., Goldman-Wohl, D., Hamani, Y., Avraham, I., Greenfield, C., Natanson-Yaron, S., Prus, D., Cohen-Daniel, L., Arnon, T.I., Manaster, I. et al., 2006. Decidual NK cell regulate key developmental processes at the human fetal-maternal interface. Nat. Med. 12, 1065-1074.

Heikkinen, J., Möttönen, M., Komi, J., Alanen, A., Lassila, O., 2003. Phenotypic characterization of human decidual macrophages. Clin. Exp. Immunol. 131, 498-505.

Hornung, D., Ryan, I.P., Chao, V.A., Vigne, J.L., Schriock, E.D., Taylor, R.N., 1997. Immunolocalization and regulation of the chemokine RANTES in human endometrial and endometriosis tissues and cells. J. Clin. Endocrinol. Metab. 82, 1621-1628. 
Huber, A.V., Saleh, L., Bauer, S., Husslein, P., Knofler, M., 2006. TNFalpha-mediated induction of PAI-1 restricts invasion of HTR-8/SVneo trophoblast cells. Placenta. 27, 127136.

Hustin, J., Jauniaux, E., Schaaps, J.P., 1990. Histological study of the materno-embryonic interface in spontaneous abortion. Placenta. 11, 477-486.

Hustin, J., Kadri, R., Jauniaux, E., 1996. Spontaneous and habitual abortion--a pathologist's point of view. Early Pregnancy. 2, 85-95.

Jauniaux, E., Hustin, J., 1992. Histological examination of first trimester spontaneous abortions: the impact of materno-embryonic interface features. Histopathology. 21, 409414.

Jauniaux, E., Zaidi, J., Jurkovic, D., Campbell, S., Hustin, J., 1994. Comparison of colour Doppler features and pathological findings in complicated early pregnancy. Hum. Reprod. 9, 2432-2437.

Jauniaux, E., Gulbis, B., Schandene, L., Collette, J., Hustin, J., 1996. Distribution of interleukin-6 in maternal and embryonic tissues during the first trimester. Mol. Hum. Reprod. 2, 239-243.

Jauniaux, E., Watson, A.L., Hempstock, J., Bao, Y.P., Skepper, J.N., Burton, G.J., 2000. Onset of maternal arterial blood flow and placental oxidative stress. A possible factor in human early pregnancy failure. Am. J. Pathol. 157, 2111-2122. 
Jokhi, P.P., King, A., Sharkey, A.M., Smith, S.K., Loke, Y.W., 1994. Screening for cytokine messenger ribonucleic acids in purified human decidual lymphocyte populations by the reverse-transcriptase polymerase chain reaction. J. Immunol. 153, 4427-4435.

Jones, R.L., Hannan, N.J., Kaitu'u, T.J., Zhang, J., Salamonsen, L.A., 2004. Identification of chemokines important for leukocyte recruitment to the human endometrium at the times of embryo implantation and menstruation. J. Clin. Endocrinol. Metab. 89, 6155-6167.

Jovanovic, M., Vicovac, L., 2009. Interleukin-6 stimulates cell migration, invasion and integrin expression in HTR-8/SVneo cell line. Placenta. 30, 320-328.

Khong, T.Y., Liddell, H.S., Robertson, W.B., 1987. Defective haemochorial placentation as a cause of miscarriage: a preliminary study. Br. J. Obstet. Gynaecol. 94, 649-655.

Lash, G.E., Schiessl, B., Kirkley, M., Innes, B.A., Cooper, A., Searle, R.F., Robson, S.C., Bulmer, J.N., 2006. Expression of angiogenic growth factors by uterine natural killer cells during early pregnancy. J. Leukoc. Biol. 80, 572-580.

Lidström, C., Matthiesen, L., Berg, G., Sharma, S., Ernerudh, J., Ekerfelt, C., 2003. Cytokine secretion patterns of NK cells and macrophages in early human pregnancy decidua and blood: implications for suppressor macrophages in decidua. Am. J. Reprod. Immunol. 50, 444-452.

Madhappan, B., Kempuraj, D., Christodoulou, S., Tsapikidis, S., Boucher, W., Karagiannis, V., Athanassiou, A., Theoharides, T.C., 2003. High levels of intrauterine corticotropin-releasing hormone, urocortin, tryptase, and interleukin-8 in spontaneous abortions. Endocrinology. $144,2285-2290$. 
Meisser, A., Cameo, P., Islami, D., Campana, A., Bischof, P., 1999. Effects of interleukin-6 (IL6) on cytotrophoblastic cells. Mol. Hum. Reprod. 5, 1055-1058.

Mjösberg, J., Berg, G., Jenmalm, M.C., Ernerudh, J., 2010. FOXP3+ regulatory T cells and T helper 1, T helper 2, and T helper 17 cells in human early pregnancy decidua. Biol. Reprod. $82,698-705$.

Murphy, S.P., Tayade, C., Ashkar, A.A., Hatta, K., Zhang, J., Croy, B.A., 2009. Interferon gamma in successful pregnancies. Biol. Reprod. 80, 848-859.

Ostensen, M., Villiger, P.M., 2007. The remission of rheumatoid arthritis during pregnancy. Semin. Immunopathol. 29, 185-191.

Otun, H.A., Lash, G.E., Innes, B.A., Bulmer, J.N., Naruse, K., Hannon, T., Searle, R.F., Robson, S.C., 2011. Effect of tumour necrosis factor-alpha in combination with interferon-gamma on first trimester extravillous trophoblast invasion. J. Reprod. Immunol. 88, 1-11.

Piccinni, M.P., Scaletti, C., Maggi, E., Romagnani, S., 2000. Role of hormone-controlled Th1and Th2-type cytokines in successful pregnancy. J. Neuroimmunol. 109, 30-33.

Pijnenborg, R., Anthony, J., Davey, D.A., Rees, A., Tiltman, A., Vercruysse, L., van Assche, A., 1991. Placental bed spiral arteries in the hypertensive disorders of pregnancy. Br. J. Obstet. Gynaecol. 98, 648-655.

Pijnenborg, R., McLaughlin, P.J., Vercruysse, L., Hanssens, M., Johnson, P.M., Keith, J.C. Jr., Van Assche, F.A., 1998. Immunolocalization of tumour necrosis factor-alpha (TNF-alpha) in the placental bed of normotensive and hypertensive human pregnancies. Placenta. 19, 231239. 
Pijnenborg, R., Vercruysse, L., Hanssens, M., 2006. The uterine spiral arteries in human pregnancy: facts and controversies. Placenta. 27, 939-958.

Pitman, H., Innes, B.A., Robson, S.C., Bulmer, J.N., Lash, G.E., 2013. Altered expression of interleukin-6, interleukin-8 and their receptors in decidua of women with sporadic miscarriage. Hum. Reprod. 28, 2075-2086.

Plevyak, M., Hanna, N., Mayer, S., Murphy, S., Pinar, H., Fast, L., Ekerfelt, C., Ernerudh, J., Berg, G., Matthiesen, L., Sharma, S., 2002. Deficiency of decidual IL-10 in first trimester missed abortion: a lack of correlation with the decidual immune cell profile. Am. J. Reprod. Immunol. 47, 242-250.

Queenan, J.T. Jr., Kao, L.C., Arboleda, C.E., Ulloa-Aguirre, A., Golos, T.G., Cines, D.B., Strauss, J.F. 3rd., 1987. Regulation of urokinase-type plasminogen activator production by cultured human cytotrophoblasts. J. Biol. Chem. 262, 10903-10906.

Radulovic, N.V., Ekerhovd, E., Abrahamsson, G., Norstrom, A., 2010. Cervical tissue changes in women with miscarriage: a morphological and biochemical investigation. Acta. Obstet. Gynecol. Scand. 89, 54-64.

Renaud, S.J., Postovit, L.M., Macdonald-Goodfellow, S.K., McDonald, G.T., Caldwell, J.D., Graham, C.H., 2005. Activated macrophages inhibit human cytotrophoblast invasiveness in vitro. Biol. Reprod. 73, 237-243.

Robson, A., Harris, L.K., Innes, B.A., Lash, G.E., Aljunaidy, M.M., Aplin, J.D., Baker, P.N., Robson, S.C., Bulmer, J.N., 2012. Uterine natural killer cells initiate spiral artery remodeling in human pregnancy. FASEB J. 26, 4876-4885. 
Saito, S., Kasahara, T., Sakakura, S., Enomoto, M., Umekage, H., Harada, N., Morii, T., Nishikawa, K., Narita, N., Ichijo, M., 1994. Interleukin-8 production by CD16-CD56bright natural killer cells in the human early pregnancy decidua. Biochem. Biophys. Res. Commun. 200, 378-383.

Salamonsen, L.A., Hannan, N.J., Dimitriadis, E., 2007. Cytokines and chemokines during human embryo implantation: roles in implantation and early placentation. Semin. Reprod. Med. 25, 437-444.

Shimoya, K., Moriyama, A., Matsuzaki, N., Ogata, I., Koyama, M., Azuma, C., Saji, F., Murata, Y., 1999. Human placental cells show enhanced production of interleukin (IL)-8 in response to lipopolysaccharide (LPS), IL-1 and tumour necrosis factor (TNF)-alpha, but not to IL-6. Mol. Hum. Reprod. 5, 885.

Sun, C., Zhang, Y.Y., Tang, C.L., Wang, S.C., Piao, H.L., Tao, Y., Zhu, R., Du, M.R., Li, D.J., 2013. Chemokine CCL28 induces apoptosis of decidual stromal cells via binding CCR3/CCR10 in human spontaneous abortion. Mol. Hum. Reprod. 19, 676-686.

Svensson, J., Jenmalm, M.C., Matussek, A., Geffers, R., Berg, G., Ernerudh, J., 2011. Macrophages at the fetal-maternal interface express markers of alternative activation and are induced by M-CSF and IL-10. J. Immunol. 187, 3671-3682.

Svensson-Arvelund, J., Ernerudh, J., 2014. The Role of Macrophages in Promoting and Maintaining Homeostasis at the Fetal-Maternal Interface. Am. J. Reprod. Immunol. In Press.

Tabibzadeh, S., 1991. Human endometrium: an active site of cytokine production and action. Endocr. Rev. 12, 272-290. 
Tabibzadeh, S., Kong, Q.F., Babaknia, A., May, L.T., 1995. Progressive rise in the expression of interleukin-6 in human endometrium during menstrual cycle is initiated during the implantation window. Hum. Reprod. 10, 2793-2799.

Takata, H., Tomiyama, H., Fujiwara, M., Kobayashi, N., Takiguchi, M. 2004. Cutting edge: expression of chemokine receptor CXCR1 on human effector CD8+ T cells. J. Immunol. 173, 2231-2235.

Tsuda, H., Sakai, M., Michimata, T., Tanebe, K., Hayakawa, S., Saito, S., 2001. Characterization of NKT cells in human peripheral blood and decidual lymphocytes. Am. J. Reprod. Immunol. 45, 295-302.

Vince, G., Shorter, S., Starkey, P., Humphreys, J., Clover, L., Wilkins, T., Sargent, I., Redman, C., 1992. Localization of tumour necrosis factor production in cells at the materno/fetal interface in human pregnancy. Clin. Exp. Immunol. 88, 174-180.

Vince, G.S., Johnson, P.M., 2000. Leucocyte populations and cytokine regulation in human uteroplacental tissues. Biochem. Soc. Trans. 28, 191-195.

Von Rango, U., Classen-Linke, I., Raven, G., Bocken, F., Beier, H.M., 2003. Cytokine microenvironments in human first trimester decidua are dependent on trophoblast cells. Fertil. Steril. 79, 1176-1186.

Wegmann, T.G., Lin, H., Guilbert, L., Mosmann, T.R., 1993. Bidirectional cytokine interactions in the maternal-fetal relationship: is successful pregnancy a TH2 phenomenon? Immunol. Today. 14, 353-356. 
Wu, H.X., Jin, L.P., Xu, B., Liang, S.S., Li, D.J., 2014. Decidual stromal cells recruit Th17 cells into decidua to promote proliferation and invasion of human trophoblast cells by secreting IL-17. Cell. Mol. Immunol. 11, 253-262.

Zenclussen, A.C., Blois, S., Stumpo, R., Olmos, S., Arias, K., Malan Borel, I., Roux, M.E., Margni, R.A., 2003. Murine abortion is associated with enhanced interleukin- 6 levels at the feto-maternal interface. Cytokine. 24, 150-160. 
Table 1: Summary of the potential role of altered decidual cytokines in the pathophysiology of spontaneous miscarriage.

\begin{tabular}{|l|l|l|}
\hline Cytokine & Role in early pregnancy & Levels in spontaneous miscarriage \\
\hline IL-6 & EVT invasion - variable results from & Serum - increased. \\
& in vitro assay systems. & Decidual leucocytes (uNK cells and \\
& VSMC disorganisation. & macrophages) - decreased. \\
\hline CXCL8/IL-8 & $\begin{array}{l}\text { EVT invasion - stimulatory. } \\
\text { Spiral artery remodelling - induces }\end{array}$ & Decidual leucocytes (uNK cells and \\
& VSMC disorganisation. & Products of conception - increased. \\
& EVT invasion - inhibitory. & Decidual stromal levels - increased. \\
\hline TNF- $\alpha$ & & \\
\hline
\end{tabular}

